\title{
Digital Evaluation of Sitting Posture Comfort in Human-Vehicle System under Industry 4.0 Framework
}

\author{
TAO Qing ${ }^{1,2}$, Jinsheng Kang**3, SUN Wenlei ${ }^{1}$, LI Zhaobo ${ }^{1}$, HUO Xiao ${ }^{1}$ \\ ${ }^{I}$ School of Mechanical Engineering, Xinjiang University, Urumqi, China 830046 \\ ${ }^{2}$ Center for Post-doctoral Studies of Mechanical Engineering, Urumqi, China 830046 \\ ${ }^{3}$ Colle of Engineering, Design and Physical Sciences, Brunel University London, Uxbridge, UB8 3PH, UK
}

\begin{abstract}
Most of the previous studies on the vibration ride comfort of the human-vehicle system were focused only on one or two aspects of the investigation. This paper proposed a hybrid approach which integrates all kinds of investigation methods in real environment and virtual environment. The real experimental environment includes the WBV (whole body vibration) test, questionnaires for human subjective sensation and motion capture. The virtual experimental environment includes the theoretical calculation on simplified 5-DOF human body vibration model, the vibration simulation and analysis within ADAMS/ Vibration ${ }^{\mathrm{TM}}$ module, and the digital human biomechanics and occupational health analysis in Jack software. While the real experimental environment provided realistic and accurate test results, it also serves as core and validation for the virtual experimental environment. The virtual experimental environment takes full advantages of current available vibration simulation and digital human modelling software, and makes it possible to evaluate the sitting posture comfort in a human-vehicle system with various human anthropometric parameters. How this digital evaluation system for car seat comfort design is fitted in the Industry 4.0 framework is also proposed.
\end{abstract}

Key words: parameter identification, vibration characteristic, sitting posture comfort, human-vehicle system, human body model, digital design, digital evaluation, Industry 4.0.

\section{Introduction}

The process of designing a new vehicle involves satisfying a large number of requirements and following multiple guidelines. Among the various vehicle design parameters, the most critical parameter that has a direct effect on users is the level of "comfort". The application of ergonomic methodologies to vehicle design processes is becoming increasingly important.

Seated postures have been regarded as potentially unhealthy factors for several musculoskeletal disorders especially in the car ${ }^{[1]}$. An occupational epidemiological study by $\mathrm{Gyi}^{[2]}$ showed that people exposed to over $4 \mathrm{~h}$ of driving per day were more than twice as likely to suffer from low back pain compared to those with over $4 \mathrm{~h}$ of sedentary work per day, and the vibration from road can lead to higher risk of musculoskeletal disorders. Sitting comfort needs could be divided into sitting comfort and discomfort. Several studies have suggested that comfort and discomfort be treated as complementary but independent entities ${ }^{[3]}$. Similarly, Hancock and Pepe ${ }^{[4]}$ showed that discomfort and comfort are at different stages of needs, the latter being placed at a higher stage than the former. In other studies, comfort was not measured and only a discomfort scale was used with supplemental objective measures such as electromyography (EMG),

* Corresponding author. E-mail: jinsheng.kang@brunel.ac.uk

Supported by National Natural Science Foundation of China (Grant No. 51465056), and Xinjiang Provincial Natural Science Foundation of China (Grant No. 2015211C265), and Xinjiang University PhD Start-up Funds. center of pressure (COP), or interface pressure ${ }^{[5]}$

Driving postures are related to both comfort and discomfort. In a study by Hanson et al. ${ }^{[6]}$, participants described their preferred driving posture using adjectives. Zhang's findings ${ }^{[3]}$ suggest that the driving posture indeed is related to both comfort and discomfort. From this, it can again be argued that subjective responses to driving postures should be rated in terms of comfort and discomfort using two separate scales. As addressed above, designing a car seat is a challenging task that must meet multiple requirements; within a confined space where vibration is generally present. Comfort is a complex construct influenced by several factors, except subjective responses the other important impact is vibration.

At the stage of developing a seat system, prediction of vibration responses at the human body-seat interface by computer simulations is required. In order to carry out such computer simulations, a dynamic model on the human body is needed, which is an effective tool to describe the simulation for ergonomics design. It also plays an important role in the prediction of the human body vibration characteristics and the impact of vibration on the human body. It was known that the vibration behavior of a human body on seat was affected by not only vibration environment ${ }^{[7-8]}$ but also the sitting posture ${ }^{[9]}$. As early as in 1974, M. Robert and others built an six degrees of freedom nonlinear vibration model of human body ${ }^{[10]}$. In 1994, W. Qassem put forward a description on human body vertical vibration and horizontal vibration as an 11 degrees of freedom vibration model ${ }^{[11]}$. In 1994, Magnusson et al created some recommendations on how to design a driver's 
cab to reduce the exposure of whole body vibration and other risk factors having a negative effect on the health ${ }^{[12]}$. In 1998, PÉ Boileau and S Rakheja proposed an 4 degrees of freedom human body vertical vibration model ${ }^{[13]}$ based on STH (seat-to-head transmissibility) and DPM (driving-point mechanical impedance). In 2005, Hyeong Kim reported a body vertical vibration model based on STH and AM (apparent mass and apparent quality) ${ }^{[14]}$. In 2008, E Zhang studied the different vibration parameters of the human body vibration characteristics ${ }^{[15]}$. Recently, Reddy $\mathrm{P}$ $S$ et al proposed a 15-DOF human body model to include the left and right lower and upper arms, as well as neck in the human-vehicle vibration model ${ }^{[16]}$. Ten subjects were tested in whole body vibration with five frequencies in vertical direction, and a hybrid Polaris spectra system was used to obtain the seat to head transmissibility ${ }^{[17]}$. Rantaharju $\mathrm{T}$ et al compared five different assessment methods for whole body vibration and shocks, and their impacts on the interpretation on the experimental results ${ }^{[18]}$.

Most of the previous studies on the vibration ride comfort of the human-vehicle system were focused only on one or two aspects of the investigation. Some of the research concentrated on human's perception ${ }^{[3,4,5]}$, while others emphasized on the sitting posture ${ }^{[6,9]}$, and many different human body vibration models were proposed and human whole body vibration test conducted ${ }^{[11-18]}$. With the rapid development of computational power, simulation software and VR (Virtual Reality) technology, it is possible to integrate all the simulation and modelling aspects together, backed up with a limited number of human whole body vibration test and questionnaire results as validation, to provide a simulation method for rapidly evaluating the sitting posture body comfort of human-vehicle systems. This paper describes the pioneer research along this line, in which a limited number of human subjects whole body vibration test together with questionnaire were conducted, a simplified 5-DOF human body vibration model was established, human body vibrations were simulated on ADAMS software platform and sitting postures were evaluated via digital human and joint angles. The application of the proposed method under Industry 4.0 framework is also discussed in this paper.

\section{Methods}

\subsection{Vibration comfort questionaire}

During a long-term drive in a dynamic environment, the driver will be exposed to whole body vibrations. The frequency range considered in the ISO 2631 standard is $0.5-80 \mathrm{~Hz}$ for health, comfort and perception, $0.1-0.5 \mathrm{~Hz}$ for motion sickness. When measuring vibration, the primary quantity of vibration magnitude should be acceleration. The measurement should be done according to a coordinate system originating at a point from which vibration is considered to enter the human body. The principal basic xyz coordinate systems are shown in the ISO 2631:1-1997 standard. The root-mean-square value of the frequency-weighted acceleration were obtained according to the ISO 2631:1-1997 standard, and they were compared with human subjective sensation acquired from the questionnaire during whole body vibration test, and are summarized in Table 1.

Table 1. Comparison table of acceleration, human subjective sensation -- vehicle riding comfort

\begin{tabular}{ll}
\hline Acceleration & Comfort Level \\
\hline Less than $0.315 \mathrm{~m} / \mathrm{s}^{2}$ & not uncomfortable \\
0.315 to $0.63 \mathrm{~m} / \mathrm{s}^{2}$ & a little uncomfortable \\
0.5 to $1 \mathrm{~m} / \mathrm{s}^{2}$ & fairly uncomfortable \\
0.8 to $1.6 \mathrm{~m} / \mathrm{s}^{2}$ & uncomfortable \\
1.25 to $2.5 \mathrm{~m} / \mathrm{s}^{2}$ & very uncomfortable \\
Greater than $2 \mathrm{~m} / \mathrm{s}^{2}$ & extremely uncomfortable \\
\hline
\end{tabular}

\subsection{Simplified 5-DOF human body vibration model}

Human body can be treated as various degree of freedom vibration systems ${ }^{[1-18]}$. The reason for us to use this simplified 5-DOF vertical human body vibration model is that this model can capture the most important features of human's perception and response to vibration in a human-vehicle system, while the model itself is simple to implement in a remote portable or distributed environment in Industry 4.0 framework. Human body is a flexible organization, and therefore the vibration responses will be similar to an elastic system. The lumped mass, torsion spring, damper, and multibody dynamics were used to model the human body vibration response characteristics. Human body was divided into five parts, which were head, torso, lower torso (including hip), the left leg and right leg. The vibration of the thigh will be passed through the whole body parts to the head. The vibration of the head is the most important factor that affects the comfort and produces visual impairment. To predict the vibration responses of the human body in a human-vehicle system under the dynamic environment, this simplified 5-DOF vertical vibration model was developed and shown in Fig.1. This is a mechanical vibration response equivalent model of a sitting posture of human body, it will treat each part of human body as the mass, stiffness, damping and so forth similar to mechanical components. As shown in Fig.1, the kinetic parameters of the model are as follows:

where $\mathrm{m}_{1}, \mathrm{~m}_{2}, \mathrm{~m}_{3}, \mathrm{~m}_{4}, \mathrm{~m}_{5}$ are the mass of human head, torso, lower torso (including hip), the left leg and right leg; $\mathrm{k}_{1}, \mathrm{k}_{2}, \mathrm{k}_{3}, \mathrm{k}_{4}, \mathrm{k}_{5}$ are the stiffness of corresponding part of the human body; $\mathrm{c}_{1}, \mathrm{c}_{2}, \mathrm{c}_{3}, \mathrm{c}_{4}, \mathrm{c}_{5}$ are the damping of each part of the human body; $\mathrm{z}_{1}, \mathrm{z}_{2}, \mathrm{z}_{3}$, $\mathrm{z}_{4}, \mathrm{z}_{5}$ are the displacement of center of gravity that each part of the human body; $\mathrm{k}_{6}, \mathrm{c}_{6}$ are the stiffness and the damping of seat; $\mathrm{z}_{0}$ is the input displacement excitation. 


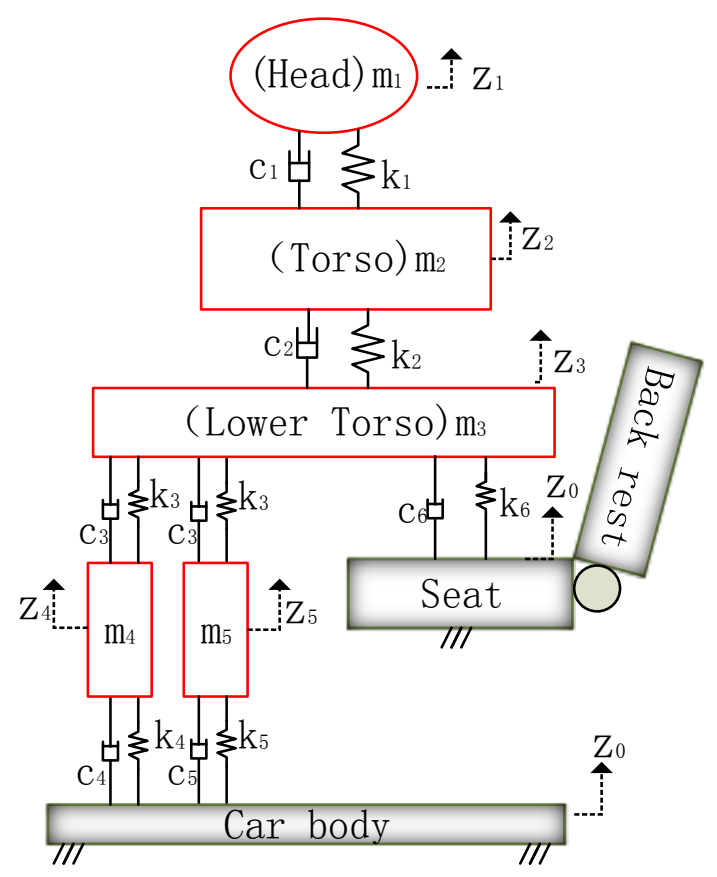

Fig.1. 5-DOF human body vibration model

According to Newton's second law, the vibration differential equation of this 5-DOF human posture model is as follows:

$$
[M]\{\ddot{z}\}+[C]\{\dot{z}\}+[K]\{z\}=[B]\{q\}
$$

Where $[\mathrm{M}],[\mathrm{K}],[\mathrm{C}]$ and $[\mathrm{B}]$ is mass matrix, stiffness matrix, damping matrix and incentive matrix of the human-vehicle system respectively; $\{z\}$ is the output vector, $\{\mathrm{z}\}=\left[\mathrm{z}_{1}, \mathrm{z}_{2}, \mathrm{z}_{3}, \mathrm{z}_{4}, \mathrm{z}_{5}\right]^{\mathrm{T}} ;\{\mathrm{q}\}$ is the excitation vector, $\{q\}=\left[Z_{0}, Z_{0}\right]^{T}$. For the convenience of the simplified model and calculation, assume that the mass, stiffness and damping of the human right leg and left leg are equal, that is $\mathrm{m}_{4}=\mathrm{m}_{5}, \mathrm{k}_{4}=\mathrm{k}_{5}, \mathrm{c}_{4}=\mathrm{c}_{5}$.

From Eq. (1), conduct the Fourier transformation,

$$
-\omega^{2}[M]\{z(j \omega)\}+j \omega[C]\{z(j \omega)\}+[K]\{z(j \omega)\}=[B]\{Q(j \omega)\}
$$

Variable $\omega$ denotes the angular frequency.

Then: $\{Q(j \omega)\}=\left[\begin{array}{c}1 \\ j \omega\end{array}\right]\left\{z_{0}(j \omega)\right\}$

$$
\text { So, } z(j \omega)=\left(-\omega^{2}[M]+j \omega[C]+[K]\right)^{-1}[B]\{Q(j \omega)\}
$$

Finally, the Available human response of transfer function is:

$$
H(\omega)=\left\{-\omega^{2}[M]+j \omega[C]+[K]\right\}^{-1}[B]\left[\begin{array}{c}
1 \\
j \omega
\end{array}\right]
$$

The Eq. (4) is the general formula of the transfer function of the human body. It is a column vector. For 5-DOF human vibration model shown in Fig.1, it is as below:

$$
H(\omega)=\left[H_{1}(\omega), H_{2}(\omega), H_{3}(\omega), H_{4}(\omega), H_{5}(\omega)\right]^{T}
$$

Where $\mathrm{H}_{1}(\omega), \mathrm{H}_{2}(\omega), \mathrm{H}_{3}(\omega), \mathrm{H}_{4}(\omega), \mathrm{H}_{5}(\omega)$ are the transfer function of the car body to human head, car body to torso, the car body to lower torso, the car body to the left leg, the car body to the right leg that each part of human body respectively. For the transfer function of car body to human head $\mathrm{H}_{1}(\omega)$, expression is as follows:

$$
H_{1}(\omega)=\frac{z_{1}(j \omega)}{z_{0}(j \omega)}
$$

The transfer function of acceleration expression is as follows:

$$
S(j \omega)=\frac{\ddot{z}_{1}(j \omega)}{\ddot{z}_{0}(j \omega)}
$$

\subsection{Whole body vibration (WBV) experiment setup}

The vibration experiment on human body was conducted on the vibration equipment manufactured in Suzhou SUSHI test instrument co., LTD, China. The test seat was a pure rigid steel seat. There were 29 participants, and they were undergraduate and postgraduate students of Xinjiang University with a male to female ratio of $6: 4$, and aged from 21 to 28 years old. Their mean stature was $173.6 \mathrm{~cm}$, and average weight was $63.4 \mathrm{~kg}$. All the participants were in good health and without skeletal and muscular disorders. Before the experiment, participants completed the general information part of the questionnaire. During the experiment they were asked to answer the questionnaire to indicate their different comfort level under the different frequency bands. The principle of experiment is shown in Fig.2. The vibration table produces the fixed frequency vibration vibrator according to the experimental requirements. Through the six acceleration sensors, the vibration signals on the human's body were recorded and saved by the oscilloscope.

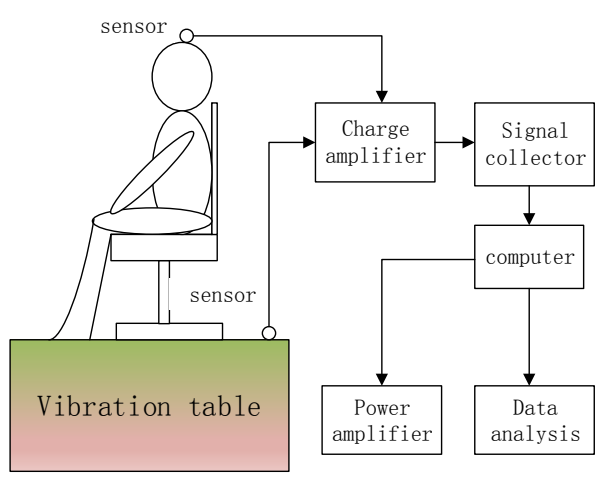

Fig.2 System diagram of whole body vibration test 
The parameter selections of human body vibration experiment were as follows: 12 frequency bands as the experimental frequencies were chosen, they were $2,2.5,3$, $3.5,4,5,6,8,10,12,16,20 \mathrm{~Hz}$ respectively. The strength of vibration was in accordance with the standards ISO 2631 , and the measurement time was $5 \mathrm{~min}$ for each frequency under the working condition.

\subsection{Vibration simulation in ADAMS software}

The virtual vibration test was conducted on ADAMS/Vibration $^{\mathrm{TM}}$, a plug-in module for MSC. ADAMS software. The center of the virtual vibration table was set up as the Input Channel, and the input signal applied was $0.3 \mathrm{~g}\left(0.3 \times 9.81 \mathrm{~m} / \mathrm{s}^{2}\right)$. The Output Channel were set on the center of mass of the head, torso, lower torso, and the lower extremities of the virtual human. we set up the acceleration output channel. Carrying out the analysis in the frequency range $0 \sim 20 \mathrm{~Hz}$, in Vibration Analysis within ADAMS/Vibration ${ }^{\mathrm{TM}}$ module, each body part's acceleration frequency response characteristics was obtained in the virtual human-vehicle system.

\section{Data Analysis and Results}

For the WBV test, the measured piezoelectric signals of acceleration were transferred into MATLAB software to go through the filtering process and conduct spectral analysis by the $\mathrm{A} / \mathrm{D}$ conversion, then the frequency response function of human body were obtained. The obtained human response transfer rates $S_{0}\left(j \omega_{i}\right)$ from the WBV test under different vibration frequencies were shown in Fig.3.

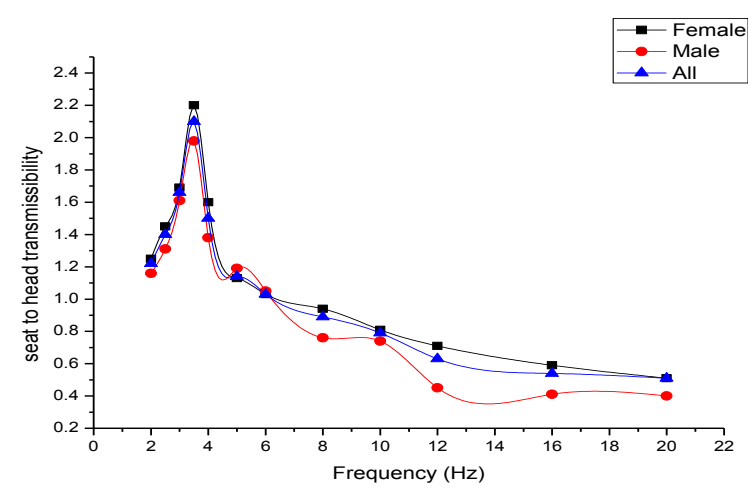

Fig. 3 Curve of seat to head transmissibility from experiment

Fig. 3 is the vibration transfer function Curve of seat to head transmissibility, which was plotted by ORIGIN software according to the experiment data. Fig.3 showed the averaged results of WBV test on all subjects. Although the whole body vibration response are different between different subjects, the difference was small, with most of the resonance peak occurred at about $4 \mathrm{~Hz}$. Meanwhile, the human body comfort level dropped significantly at around the 4-5 Hz. The questionnaire results showed that the results of the WBV test and the subjective sensation from questionnaires were coinciding.

For the theoratical calculation of the simplified 5-DOF human body vibration model, the whole process of identifying human body dynamic characteristics was accomplished in MATLAB optimization toolbox. In this process, the constants for each part of the human body were referred to GB/T 17245-2004 which is a Chinese national standard of adult human body inertia parameters. The constants of stiffness and damping in each part of human body were $50 \leqslant \mathrm{ci} \leqslant 100000 \mathrm{Ns} / \mathrm{m}(\mathrm{i}=1,2,3,4,5,6) ; \mathrm{k} 1, \mathrm{k} 4$, $\mathrm{k} 5, \mathrm{k} 6 \geqslant 0 \mathrm{kN} / \mathrm{m} ; 50 \leqslant \mathrm{k} 2, \mathrm{k} 3 \leqslant 300 \mathrm{kN} / \mathrm{m}$.

Fig 4 shows the theoretical calculation curve obtained from the 5-DOF human body vibration model, in contrast with the WBV experiment obtained transfer function curve. The trends of the two curves are basically the same, with resonance peaks appeared at about $4 \mathrm{~Hz}$.

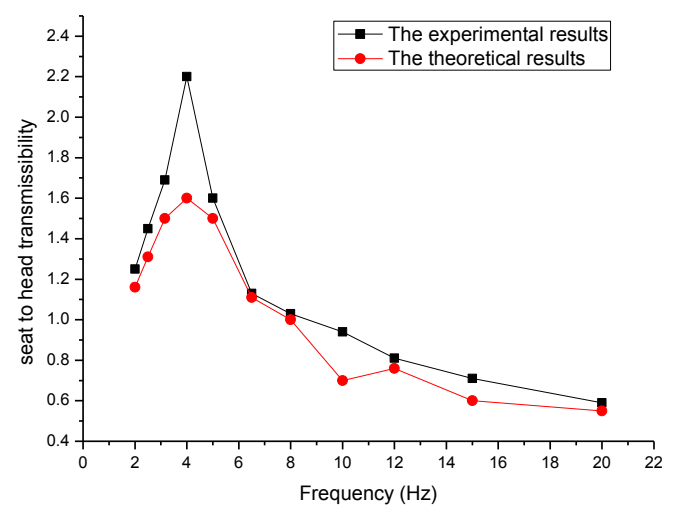

Fig. 4 The comparison of the two curves of the transmissibility from experiment and theoretical calculation

Carrying out the Laplace transform on equation (1), the transfer function of acceleration for each part of human body was analyzed in frequency domain. In this analysis, the frequency range was set from 0 to $20 \mathrm{~Hz}$, using MATLAB to solve the Bode diagram command bode, the transfer function Bode diagram for all parts of the human body displacement, velocity and acceleration were obtained. The resonance frequency of four parts of the human body were different, the resonant frequency of the head, torso and lower torso (including hip) were around $4 \mathrm{HZ}$, and the resonance frequency of the left and right lower limb were around $12 \mathrm{HZ}$.

The human body acceleration frequency response characteristics of the simulated virtual human-vehicle vibration system obtained from ADAMS/Vibration software were basically identical to the result obtained from 5-DOF human body vibration theoretical calculation model. The resonance frequencies, for the head, torso, and lower torso were concentrated in $4 \mathrm{~Hz}$, and lower limbs were at around $12 \mathrm{~Hz}$. The ADAMS simulation results 
further confirmed that the 5-DOF human body vibration model and the human body vibration characteristic analysis we made were accountable.

\section{Application of Digital Human Model in Sitting Posture Comfort Evaluation}

\subsection{The digital human model}

The application of digital human (virtual human/manikin) is a new trend in industry and design practice for ergonomics evaluation. For example, Jack and RAMSIS are the two mainstream software widely used in automobile industry. These software have the capability to evaluate the human sitting posture from biomechanics perspective for comfort and fatigue assessment. They can be easily connected to motion capture system so that realistic human sitting posture inside a vehicle can be streamed in. Another advantage is that virtual human's gender, height, weight and any anthropometric parameter can be set conveniently, so that the ergonomics evaluation can be conducted on a wider population. Unfortunately, these virtual human software do not have the capability to do the vibration simulation.

In our previous research, we have obtained some useful sitting posture data ${ }^{[19]}$. In these experiments, the hardware used to capture the body motion of participants was the Motion Analysis Eagle Digital System (Fig. 5). This is an optical motion capture system, consisting of Digital Cameras, the Eagle Hub, to which all cameras are connected and uplinks to a computer terminal. All the hardware components are controlled by EVaRT Real Time software. It is within this software where all data is recorded, processed and displayed, and where post processing takes place. Fig 6 shows the generated skeleton model which then be exported to Jack software for occupational health analysis.

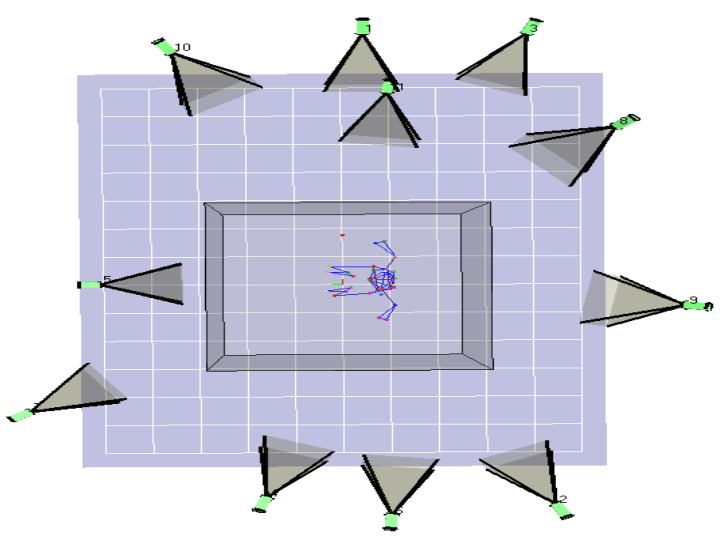

Fig.5 Motion capture system camera setup

The analysis of the data was accomplished using a self-developed program in MATLAB. A total of 20 joint angles were evaluated in relation to the sitting posture and body motion tasks. The definition of joint angles was made with reference to $G$. Andreoniet et $\mathrm{al}^{[20]}$, and with reference to other joint angle definition conventions as well. Using a self-developed program in MATLAB, the joint angle were calculated, and compared with the occupational health analysis, like fatigue etc. in Jack software.

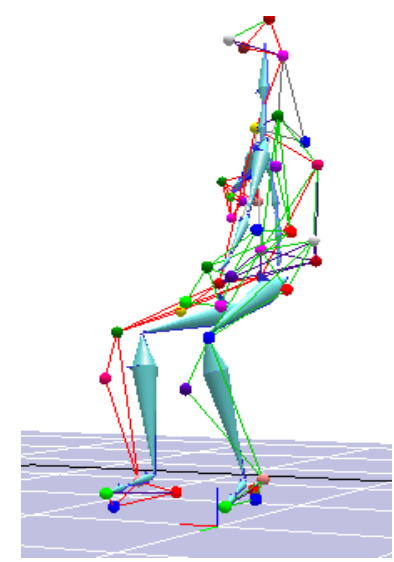

Fig.6 Sitting posture skeleton model generated

\subsection{Sitting posture knowledge base}

Although motion capture system provided a mean to capture human body posture and motion in a realistic way, it is not possible to do motion capture for the wide population with all different anthropometric parameters. A realistic way would be to collect some motion capture data on sitting posture from typical and extreme sized subjects, and conduct biomechanics and occupational health analysis. Through interpolation and extrapolation, the sitting posture knowledge base for all population with all different anthropometric parameters can be established, with corresponding biomechanics and occupational health analysis values as index. This constitutes part of the knowledge base for the digital evaluation of sitting posture comfort in human-vehicle system.

\subsection{Hybrid system for sitting posture evaluation}

Similarly to the motion capture techniques, human subjects WBV (whole body vibration) test could not be applied to a wide population. Actually, all the reported WBV experiment were conducted on a very limited number of human subjects, from several to one or two dozens of. The limited number of WBV test results can be interpolated and extrapolated, with the guideline from the theoretical calculation model of human body vibration. These data, together with the human subjective perception obtained from questionnaires, constitute another part of the knowledge base for the digital evaluation of sitting posture comfort in human-vehicle system.

Fig.7 shows the proposed hybrid system for sitting posture comfort evaluation, which consists of two experimental environments: real and virtual. The real experimental environment includes the WBV (whole body vibration) test, questionnaires for human subjective sensation and motion capture. The virtual experimental 
environment includes the theoretical calculation on simplified 5-DOF human body vibration model, the vibration simulation and analysis within ADAMS/ Vibration ${ }^{\mathrm{TM}}$ module, and the digital human biomechanics and occupational health analysis in Jack software. While the real experimental environment provided realistic and accurate test results, it also serves as core and validation for the virtual experimental environment. The virtual experimental environment takes full advantages of current available vibration simulation and digital human modelling software, and makes it possible to evaluate the sitting posture comfort in a human-vehicle system with various human anthropometric parameters.

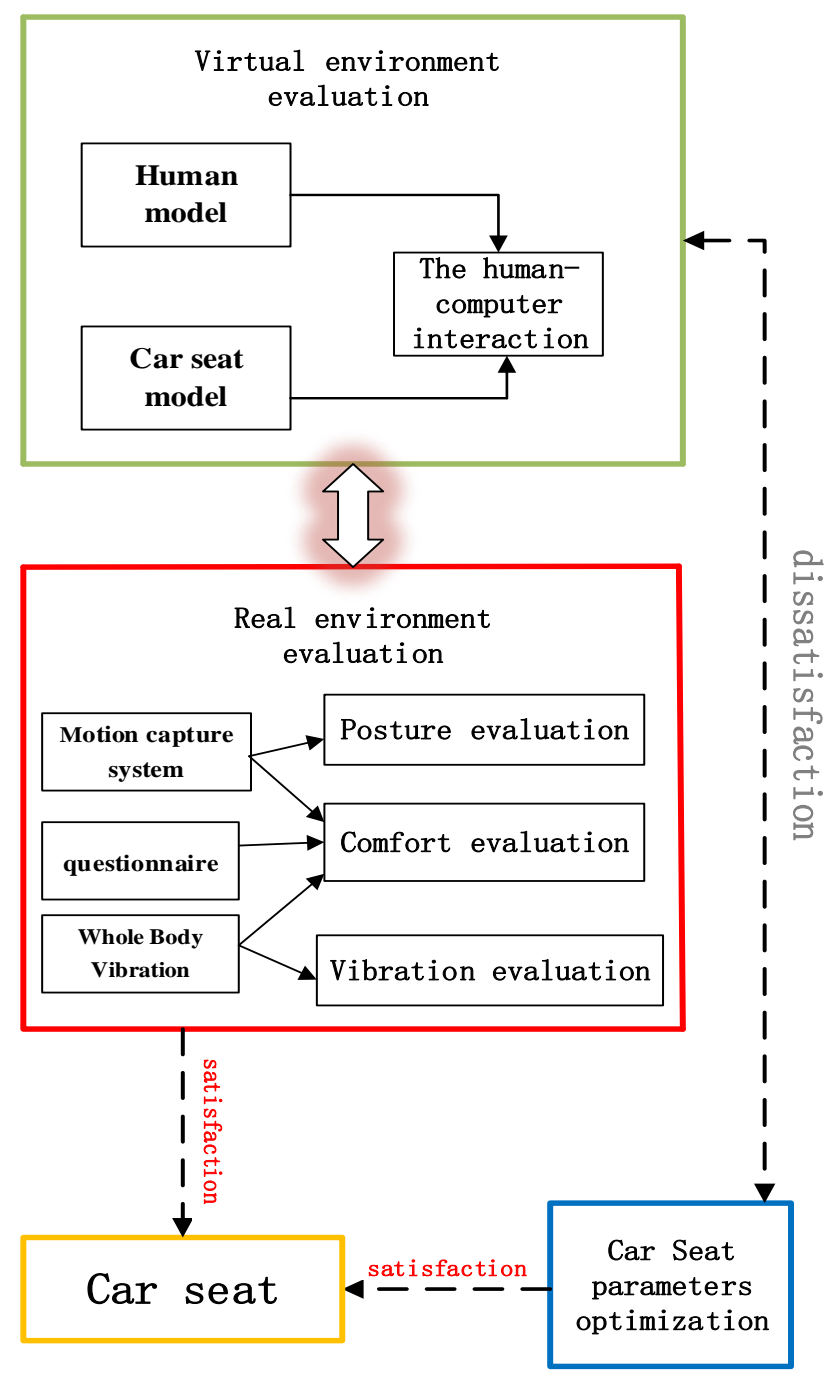

Fig. 7 Hybrid system for sitting posture evaluation

\section{Discussion on How the System Being Fitted in Industry 4.0 Framework}

Industry 4.0 represented the trend and direction of fourth industrial revolution. It was recognized there are four key components and six design principles within Industry 4.0 framework $^{[21]}$. It seems that they are all related to digital evaluation, and digital evaluation can contribute to the implementation of the four key components and six design principles in Industry 4.0, as indicated in Table 2.

Table 2 Contribution of digital evaluation to Industry 4.0

\begin{tabular}{lc}
\hline $\begin{array}{l}\text { Industry 4.0 components } \\
\text { \& design principles }\end{array}$ & $\begin{array}{c}\text { Digital evaluation could } \\
\text { contribute to its implementation }\end{array}$ \\
\hline Cyber-Physical Systems & $\sqrt{ }$ \\
Internet of Things & $\sqrt{ }$ \\
Smart Factory & $\sqrt{ }$ \\
Internet of Services & $\sqrt{ }$ \\
\hline Interoperability & $\sqrt{ }$ \\
Virtualization & $\sqrt{ }$ \\
Decentralization & $\sqrt{ }$ \\
Real-Time Capability & $\sqrt{ }$ \\
Service Orientation & $\sqrt{ }$ \\
Modularity & $\sqrt{ }$ \\
\hline
\end{tabular}

For example, Cyber-Physical Systems means higher level of integration and combination of physical and computational elements and processes, in which digital evaluation will be inevitable. Virtualization, Decentralization, Real-Time Capability and Modularity will all need digital evaluation to be integrated into the digital design and digital manufacturing circle under Internet of Things, Internet of Services and Smart Factory environment, to deliver best product and service to customer.

Fig 8 shows how the current digital evaluation of car seat comfort is fitted in the Industry 4.0 framework. Currently all the car component and assembly design are carried out in CAD software, like SolidWorks, NX, or CATIA etc.. The car dynamic simulation can be conducted in Adams - Car, Adams - Chassis environment. The identified vibration parameters of car body and car seat from these dynamic simulations will be the input to the car sitting comfort evaluation, which contains both computer simulation and the knowledge of human perception on riding comfort obtained under real human vibration test. After the sitting comfort evaluation, the results can be fed to the design of car, and also the manufacturing process simulation can be performed, for example, under Siemens FactoryCAD, FactoryFLOW, Plant Simulation, RealNC, etc.. These processes will be within the Cyber-Physical Systems and Smart Factory environment, in which the integrated simulation and synthesis, remote visualization for human and collaborative diagnostics and decision making are considered to be the core elements at cognition level ${ }^{[22]}$. The interaction with customers can be achieved through Internet of Things and Internet of Services. Service Orientation will be offered both internally and across company borders, based on customer specific 
requirements ${ }^{[21]}$.

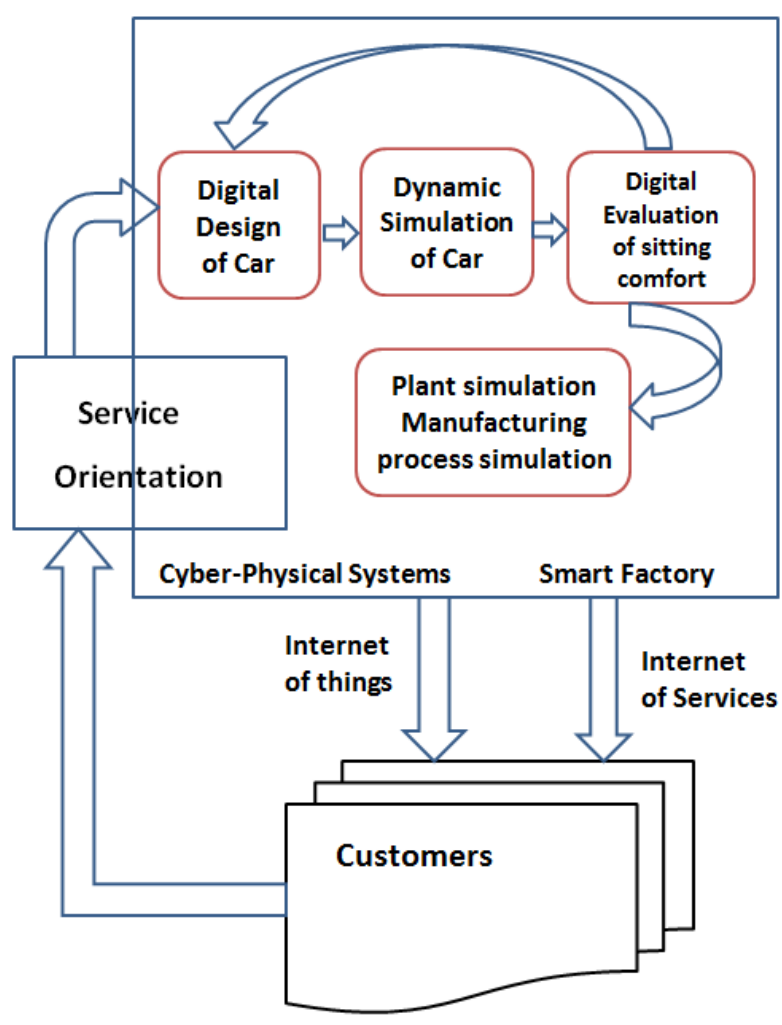

Fig 8 How the digital evaluation of car seat comfort is fitted in the Industry 4.0 framework

\section{Conclusion}

The communication, integration and synthesis between different simulated and physical systems are considered to be one of the core aspects in the implementation of Industry 4.0 $0^{[21.22]}$. Most of the previous research on sitting posture comfort in human-vehicle system were concentrated on one or two experimental methods. This paper explored an integrated approach for digital evaluation of sitting posture comfort in human-vehicle system which takes advantages from all experimental methods in real environment and virtual environments. In real environment, WBV (whole body vibration) test, questionnaires for human subjective sensation and motion capture were conducted on a limited number of subjects; while in the virtual environment, the vibration simulation and digital human biomechanics and occupational health analysis can be extended to unlimited number of manikins with all possible anthropometric parameters. The role of the experiments conducted in real environment is to validate the simulation in virtual environment. The role of the simulation in virtual environment is to generate quick assessment results in digital evaluation of sitting posture comfort in human-vehicle system for potential customers with various anthropometric parameters. Finally, how this digital evaluation system for car seat comfort design is fitted in the Industry 4.0 framework is proposed, and open for discussion.

\section{References}

[1] Rajput, B., Abboud, R.J., 2007. The inadequate effect of automobile seating on foot posture and callus development. Ergonomics 50 (1), $131-137$.

[2] Gyi, D.E., 1996. Driver Discomfort: Prevalence, Prediction and Prevention. Loughborough University, UK.

[3] Zhang, L., Helander, M., Drury, C., 1996. Identifying factors of comfort and discomfort. Human Factors 38 (3), 377 - 389.

[4] Hancock, P.A., Pepe, A.A., 2005. Hedonomics: the power of positive and pleasurable ergonomics. Ergonomics in Design 13 (1), 8 $-14$.

[5] Fenety, P.A., Putnam, C., Walker, J.M., 2000. In-chair movement: validity, reliability and implications for measuring sitting discomfort. Applied Ergonomics 31 (4), 383 - 393.

[6] Hanson, L., Sperling, L., Akselsson, R., 2006. Preferred car driving posture using 3-D information. International Journal of Vehicle Design 42 (1/2), 154 - 169.

[7] M.J.Griffin. Handbook of Human Vibration, Academic Press, London, 1990.

[8] S.Rakheja,R.G.Dong,S.Patra,P.-EBoileau,P.Marcotte,C.Warren,Biod ynamics of the human body under whole-body vibration: synthesis of the reported data, International Journal of Industrial Ergonomics 40 (2010)710-732.

[9] W.Wang, S.Rakheja, P.-E.Boileau, Relation between measured apparent mass and seat-to-head transmissibility response of seated occupants exposed to vertical vibration, Journal of Sound and Vibration 314 (2008)907-922.

[10] Robert M, Charles DN. A model for the response of seated humans to sinusoidal displacements of the seat [J].Journal of Biomechanics, 1974, 7(3):209-215.

[11] W. Qassem, MO Othman, S Abdul-Majeed. The effects of vertical and horizontal vibrations on the human body [J].Medical Engineering and Physics, 1994, 16(2):151-161.

[12] Magnusson M. L., Pope M.H., Wilder D.G. \& Areskoug B. Are occupational drivers at an increased risk for developing musculoskeletal disorders? Spine International Journal, 1996, v21, n6, Mar 15, p710-717.

[13] PÉ Boileau, S Rakheja. Whole-body vertical bio-dynamic response characteristics of the seated vehicle driver measurement and model development $[\mathrm{J}]$. International Journal of Industrial Ergonomics, 1998, 22(6):449-472.

[14] TH Kim, YT Kim, YS Yoon. Development of a biomechanical model of the human body in a sitting posture with vibration transmissibility in the vertical direction[J]. International Journal of Industrial Ergonomics, 2005, 35(9):817-829.

[15] ZHANG E, XU Lin-an, et al. Dynamic modeling and vibration characteristics of multi-DOF upper part system of seated human body[J].Journal of Engineering Design, 2008, 15(4): 244-249. (in Chinese)

[16] Reddy P S, Ramakrishna A and Ramji K. Study of the dynamic behavior of a human driver coupled with a vehicle [J]. Proc IMechE Part D: J Automobile Engineering, 2015, 229(2): 226-234.

[17] Li W, Zhang M, Lv G, et al. Biomechanical response of the musculoskeletal system to whole body vibration using a seated driver model $[\mathrm{J}]$. International Journal of Industrial Ergonomics, 2015, 45(2): 91-97.

[18] Rantaharju T, Mansfield N J, Ala-Hiiro J M et al. Predicting the health risks related to whole-body vibration and shock: a comparison of alternative assessment methods for high-acceleration events in vehicles [J]. Ergonomics, 2015, 58(7): 1071-1087. 
[19] TAO Qing, Jinsheng Kang, Stephan Orphanides, Jie Hong, SUN Wenlei, Application of JACK on evaluation of a split seat chair, Proceedings of the 19th International Conference on Automation and Computing (ICAC), IEEE, 2013, 1-6.

[20] G. Andreoniet, Giorgio C. Santambrogio. Method for the analysis of posture and interface pressure of car drivers. Journal of Applied Ergonomics, 2002, Vol. 33, 511-522.

[21] Hermann M, Pentek T, Otto B, 2015: Design Principles for Industrie 4.0 Scenarios: A Literature Review.

[22] Jay Lee, Behrad Bagheri, Hung-An Kao. A Cyber-Physical Systems architecture for Industry 4.0-based manufacturing systems[J]. Manufacturing Letters, 2015, Vol. 3, 18-23.

\section{Biographical notes}

TAO Qing, born in 1978, is currently an associate professor at Xinjiang University, China. He received his MSc degree from Huazhong University of Science and Technology, China, in 2003, and received his $\mathrm{PhD}$ degree from Xinjiang University, China, in 2015. His research interests include mechanical design and industrial design.

Tel: +86-991-8592301; E-mail: xjutao@qq.com

Jinsheng Kang, born in 1952, is currently a Senior Lecturer at Brunel University London, UK. He received his PhD degree from Bournemouth University, UK in 2001. His research interests include human modelling and simulation, $\mathrm{CAD}$, industrial design. Tel: +44-1895-266330; E-mail: Jinsheng.kang@brunel.ac.uk

SUN Wenlei, born in 1962, is currently a professor at Xinjiang University, China. He received his $\mathrm{PhD}$ degree from Huazhong University of Science and Technology, China, in 2012. His research interests include mechanical design, CAD, advanced manufacturing.

Tel: +86-991-8592308; E-mail: Sunwenxj@163.com

LI Zhaobo, born in 1994, is currently an MSc candidate at School of Mechanic Engineering, Xinjiang University, China.

E-mail: liangshanlzb@163.com

HUO Xiao, born in 1993, is currently an MSc candidate at School of Mechanic Engineering, Xinjiang University, China.

E-mail: 1505054791@qq.com 